\title{
Staircase Currents in Motoneurons: Insight into the Spatial Arrangement of Calcium Channels in the Dendritic Tree
}

\author{
Kevin P. Carlin, ${ }^{3 *}$ Tuan V. Bui, ${ }^{2 *}$ Yue Dai, ${ }^{3}$ and Robert M. Brownstone ${ }^{1,2}$ \\ Departments of ${ }^{1}$ Surgery (Neurosurgery) and ${ }^{2}$ Anatomy and Neurobiology, Dalhousie University, Halifax, Nova Scotia B3H 1X5, Canada, and ${ }^{3}$ Department \\ of Physiology, University of Manitoba, Winnipeg, Manitoba R3T 2N2, Canada
}

In spinal motoneurons, activation of dendritically located depolarizing conductances can lead to amplification of synaptic inputs and the production of plateau potentials. Immunohistochemical and computational studies have implicated dendritic $\mathrm{Ca}_{\mathrm{V}} 1.3 \mathrm{channels}$ in this amplification and suggest that $\mathrm{Ca}_{\mathrm{V}} 1.3$ channels in spinal motoneurons may be organized in clusters in the dendritic tree. Our goal was to provide physiological evidence for the presence of multiple discrete clusters of voltage-gated calcium channels in spinal motoneurons and to explore the spatial arrangement of these clusters in the dendritic tree. We recorded voltage-gated calcium currents from spinal motoneurons in slices of mature mouse spinal cords. We demonstrate that single somatic voltage-clamp steps can elicit multiple inward currents with varying delays to onset, resulting in a current with a "staircase"-like appearance. Recordings from cultured dorsal root ganglion cells at different stages of neurite development provide evidence that these currents arise from the unclamped portions of the dendritic tree. Finally, both voltage- and current-clamp data were used to constrain computer models of a motoneuron. The resultant simulations impose two conditions on the spatial distribution of $\mathrm{Ca}_{\mathrm{V}}$ channels in motoneuron dendrites: one of asymmetry relative to the soma and another of spatial separation between clusters of $\mathrm{Ca}_{\mathrm{V}}$ channels. We propose that this compartmentalization would provide motoneurons with the ability to process multiple sources of input in parallel and integrate this processed information to produce appropriate trains of action potentials for the intended motor behavior.

\section{Introduction}

Spinal motoneurons have extensive, long, branched dendrites (Cullheim et al., 1987; Burke and Glenn, 1996) that receive synaptic contacts across their entirety (Fyffe, 2001). In the absence of voltage-activated channels, distal synapses would have minimal effect on the spike initiation zone (Rall et al., 1967; Cushing et al., 2005). However, voltage-activated calcium currents in motoneuron dendrites, which generate "persistent inward currents" (PICs), appear to ensure integration of even distal inputs (Heckman et al., 2003; Li and Bennett, 2003). PICs generate plateau potentials (Hounsgaard and Kiehn, 1989; Lee and Heckman, 1996) and amplify synaptic inputs to motoneurons, both excitatory (Brownstone et al., 1994; Bennett et al., 1998; Lee and Heckman, 2000; Jones and Lee, 2006; Powers et al., 2008) and inhibitory (Hultborn et al., 2003; Kuo et al., 2003; Bui et al., 2008a).

The degree of amplification of a synaptic input depends in part on the location of the input relative to the channels mediating PICs. The calcium component of the PICs derives from $\mathrm{Ca}_{\mathrm{V}} 1$

\footnotetext{
Received 0ct. 20, 2008; revised Feb. 16, 2009; accepted March 16, 2009.

This study was supported by the Manitoba Health Research Council and the Canadian Institutes of Health Research. T.V.B. was supported by a Nova Scotia Health Research Foundation postdoctoral fellowship. We thank Jesse Lackman for assisting with the computational modeling, Pratip Mitra for helpful discussions, and Deborah Manchur for her technical assistance.

*K.P.C. and T.V.B. contributed equally to this work.

Correspondence should be addressed to Robert M. Brownstone, Department of Anatomy and Neurobiology, Dalhousie University, 14A Tupper Building, 5850 College Street, Halifax, NS B3H 1X5, Canada. E-mail: rob.brownstone@dal.ca.

K. P. Carlin's present address: Discovery Research, Purdue Pharma LP, Cranbury, NJ 08512.

DOI:10.1523/JNEUROSCI.5458-08.2009

Copyright $\odot 2009$ Society for Neuroscience $\quad$ 0270-6474/09/295343-11\$15.00/0
}

(L-type) channels (Hounsgaard and Mintz, 1988), likely $\mathrm{Ca}_{\mathrm{V}} 1.3$ (Carlin et al., 2000; Heckman et al., 2003). Whole-cell voltageclamp studies revealed delayed onset, dihydropyridine-sensitive calcium currents during depolarizing voltage steps and hysteretic currents during triangular voltage ramps (Carlin et al., 2000). These currents are thought to arise from unclamped membrane (i.e., dendrites) and correlate with immunohistochemical evidence of $\alpha_{1} 1.3$ subunits in clusters along the dendrites (Carlin et al., 2000; Simon et al., 2003; Ballou et al., 2006). Furthermore, the possibility that the channels mediating PICs are distributed in spatially segregated regions of the dendritic tree of spinal motoneurons has been hypothesized by both computational (Elbasiouny et al., 2006; Grande et al., 2007a) and electrophysiological studies. For example, Heckman and Lee (1999) demonstrated the presence of synaptic amplification on a background of ongoing bistable firing. Hultborn et al. (2003) demonstrated graded amplification of synaptic inputs during activation of the plateau currents with slow depolarizing ramps. Prather et al. (2001) reported that the amplification of synaptic excitation of motoneurons produced by combined stimulation of two separate afferent inputs approximated the algebraic sum of the amplification of each input stimulated alone. All these data suggest at least two distinct amplification sites on the dendritic trees of motoneurons.

The present study builds on these observations by demonstrating multiple discrete calcium currents originating from the unclamped dendrites. We demonstrate that, in response to somatic voltage-clamp steps, motoneurons display multiple, discrete steps of inward calcium current, producing a "staircase" appearance. A biological model of cultured dorsal root ganglion 
(DRG) neurons and a multicompartment computer model were used to support the hypothesis that these staircase currents result from the sequential activation of asymmetrically distributed and spatially segregated calcium channel clusters on dendrites. These findings suggest an organization whereby multiple dendritic compartments are defined by separated regions of $\mathrm{Ca}_{\mathrm{V}} 1.3$ channels. We propose that this organization allows motoneurons to process a multitude of inputs in parallel and to integrate this processed information, thereby ensuring output required for the intended motor behavior.

\section{Materials and Methods}

Spinal cord slice preparation. The isolation of the spinal cord and preparation of the slices is as described previously (Carlin et al., 2000). Briefly, postnatal day 8 (P8) to $\mathrm{P} 13 \mathrm{BALB} / \mathrm{c}$ mice were anesthetized with an intraperitoneal injection of ketamine $(100 \mathrm{mg} / \mathrm{kg})$ and partially submerged in ice water for $\sim 2-3$ min before decapitation and evisceration. The lumbar enlargements of the spinal cords were then dissected free in cold $\left(<4^{\circ} \mathrm{C}\right)$ dissecting artificial CSF $(\mathrm{aCSF})$ and sliced $(150-200 \mu \mathrm{m})$ in a vibrating microtome (Leica VT 1000E). Slices 150-200 $\mu \mathrm{m}$ thick were prepared and then immediately placed into warm $\left(36^{\circ} \mathrm{C}\right)$ recovery aCSF for at least $45 \mathrm{~min}$ before being transferred to a recording chamber (Warner Instruments). The largest cells in the ventral horn, presumed to be motoneurons (Carlin et al., 2000), were selected for study.

Calcium current/potential recordings. Whole-cell patch-clamp recordings were made using Sylgard-coated patch pipettes (3-4 M $\Omega$ ), an Axopatch $1 \mathrm{D}$ patch-clamp amplifier $(\beta=0.1$ head stage $)$, and pClamp software (Molecular Devices). Data were low-pass filtered at $2 \mathrm{kHz}$ and digitized at $10 \mathrm{kHz}$ with a Digidata $1200 \mathrm{~A}$ analog-to-digital (A/D) converter (Molecular Devices). Series resistance values were determined using the membrane test tool in the software and were altered by adjusting the amount of compensation. Linear leak correction of current traces was performed post hoc by subtraction of an appropriately scaled current determined from a $10 \mathrm{mV}$ hyperpolarizing pulse. Reported potentials were corrected for a $3 \mathrm{mV}$ liquid junction potential between the pipette and the recording solution in which the pipette was zeroed before obtaining a gigaohm seal. All experiments were performed at room temperature. Analyses were performed with Clampfit (Molecular Devices) and CorelDraw v12 (Corel Corporation) software packages.

The dissecting aCSF used to isolate the spinal cord contained the following (in mM): $25 \mathrm{NaCl}, 188$ sucrose, $1.9 \mathrm{KCl}, 1.2 \mathrm{NaH}_{2} \mathrm{PO}_{4}, 10 \mathrm{MgSO}_{4}$, $26 \mathrm{NaHCO}_{3}$, and 25 glucose. The warm recovery aCSF contained the following: $119 \mathrm{~mm} \mathrm{NaCl}, 1.9 \mathrm{~mm} \mathrm{KCl}, 1.2 \mathrm{~mm} \mathrm{NaH}_{2} \mathrm{PO}_{4}, 10 \mathrm{~mm} \mathrm{MgSO}_{4}$, $1 \mathrm{~mm} \mathrm{CaCl}_{2}, 26 \mathrm{~mm} \mathrm{NaHCO}_{3}, 10 \mathrm{~mm}$ glucose, $1.5 \mathrm{~mm}$ kynurenic acid (RBI), 2 mm lactic acid, and 3\% dextran. The room temperature aCSF was the same as the recovery aCSF without the kynurenic acid and dextran. To record calcium currents, the pipette solution contained the following (in $\mathrm{mm}$ ): 100 Cs-methane-sulfonate, 30 tetraethylammonium (TEA)-Cl, $1 \mathrm{MgCl}_{2}, 10$ EGTA, 10 HEPES, $0.5 \mathrm{CaCl}_{2}, 5 \mathrm{NaCl}, 3 \mathrm{ATP}-\mathrm{Mg}$, $0.3 \mathrm{GTP}$, and 0.1 leupeptin. In some experiments $10-20 \mathrm{~mm}$ sucrose was added to the intracellular solution to stabilize the series resistance (Jonas et al., 1998). The extracellular solution contained the following: $86 \mathrm{~mm}$ $\mathrm{NaCl}, 30$ mм TEA-Cl, $1.9 \mathrm{~mm} \mathrm{KCl}, 1.2 \mathrm{~mm} \mathrm{NaH} \mathrm{PO}_{4}, 26 \mathrm{~mm} \mathrm{NaHCO}_{3}, 5$ $\mathrm{mm} \mathrm{MgCl}_{2}$, $10 \mathrm{~mm}$ glucose, $4 \mathrm{~mm}$ 4-AP, $2 \mathrm{~mm} \mathrm{CsCl}, 1-3 \mathrm{~mm} \mathrm{CaCl}_{2}$, and 1 $\mu \mathrm{M}$ TTX. All bicarbonate buffered solutions were oxygenated with $95 \%$ $\mathrm{O}_{2} / 5 \% \mathrm{CO}_{2}$. The L-type calcium channel activator FPL $64176(2,5-$ dimethyl-4-[2-(phenylmethyl)benzoyl]-1H-pyrrole-3-carboxylic acid methylester) $(5.8-11.6 \mu \mathrm{m}$; RBI) was present in the extracellular solution in three of five experiments when recording calcium plateau potentials.

Dorsal root ganglion neuron preparation. DRGs were harvested from postnatal (P3-P7) Sprague Dawley rats or were obtained from Lonza. For harvesting DRGs, after anaesthetization with ketamine $(100 \mathrm{mg} / \mathrm{kg})$ and removal of the spinal cords, fine forceps were used to remove the ganglia in Eagle's balanced salt solution (Invitrogen) under sterile conditions. The ganglia were then placed in a conical tube containing Ham's F-12 nutrient media and 2.5\% trypsin (Invitrogen). After $20 \mathrm{~min}$, the digested tissue was rinsed (three times) with fresh F-12 solution containing 10\% fetal calf serum. The tissue was then triturated with a plastic pipette and plated on poly-D-lysine/laminin coated coverslips (BD Biosciences) in Neurobasal media supplemented with B27 (Invitrogen) and $50 \mathrm{ng} / \mathrm{ml}$ $2.5 \mathrm{~S}$ mouse NGF (Sigma). The cells were then incubated at $37^{\circ} \mathrm{C}$ until used ( $>45 \mathrm{~min}$ ). Samples obtained from Lonza were thawed and cultured in the same manner as the harvested DRGs. Coverslips containing DRGs were transferred to a recording chamber on an inverted microscope, in which neurons were visually patch clamped at room temperature. Voltage-gated sodium currents were recorded using an Axoclamp 200B amplifier and digitized with a Digidata 1300 series A/D converter (Molecular Devices). Again the pClamp software suite (Molecular Devices) was used for acquisition and analysis. Data were filtered at 5-10 $\mathrm{kHz}$ and digitized at $10-50 \mathrm{kHz}$.

To record sodium currents, the pipette solution contained the following (in mM): $140 \mathrm{Cs}-\mathrm{F}, 10 \mathrm{NaCl}, 10$ HEPES, and 1 or 11 EGTA. The recording chamber was continually perfused with HBSS (Invitrogen) supplemented with the following: $10 \mathrm{~mm}$ HEPES, $0.4 \mathrm{mM} \mathrm{CdCl}_{2}, 0.1 \mathrm{~mm}$ $\mathrm{NiCl}_{2}$, and 250 nм TTX. Osmoloarity was adjusted with D-manitol. The HBSS contained the following (in mM): $1.26 \mathrm{CaCl}_{2}, 0.493 \mathrm{MgCl}_{2}-6 \mathrm{H}_{2} \mathrm{O}$, $0.407 \mathrm{MgSO}_{4}-7 \mathrm{H}_{2} \mathrm{O}, 5.33 \mathrm{KCl}, 0.441 \mathrm{KH}_{2} \mathrm{PO}_{4}, 4.17 \mathrm{NaHCO}_{3}, 137.93$ $\mathrm{NaCl}, 0.338 \mathrm{Na}_{2} \mathrm{HPO}_{4}$, and 5.56 glucose.

Motoneuron model. Using the anatomical data reported by Li et al. (2005) for neonatal mouse motoneurons, we built a simplified model of a motoneuron to explore the possible distribution of $\mathrm{Ca}_{\mathrm{V}} 1.3$ channels on motoneurons capable of reproducing the voltage and current recordings described in this study. The geometry of the motoneuron consisted of a somatic compartment with seven dendrites attached. Each dendrite consisted of a proximal, middle, and distal compartment. Two of the dendrites had $\mathrm{Ca}_{\mathrm{V}} 1.3$ channels incorporated in various distributions (except when noted in the text). The geometry and density of $\mathrm{Ca}_{\mathrm{V}} 1.3$ channels of the different compartments is described in Table 1. The cell body area was $3000 \mu \mathrm{m}^{2}$.

The value of the specific resistivity of the cytoplasm $\left(R_{\mathrm{i}}\right)$ selected for this study, $70 \Omega / \mathrm{cm}$, is based on calculations for motoneurons (Barrett and Crill, 1974) and is close to the value for saline (Hille, 2001). The specific resistivity of the membrane $\left(R_{\mathrm{m}}\right)$ was set to $15,000 \Omega / \mathrm{cm}^{2}$. The specific membrane capacitance $\left(C_{m}\right)$ was set to $1 \mu \mathrm{F} / \mathrm{cm}^{2}$ (Hille, 2001). The input resistance of our models was in the range of 80-90 $\mathrm{M} \Omega$.

Several dendritic distributions patterns were explored for the $\mathrm{Ca}_{\mathrm{V}} 1.3$ channels (Bui et al., 2006; Elbasiouny et al., 2006; Grande et al., 2007a). The conductance of the $\mathrm{Ca}_{\mathrm{V}} 1.3$ channels $g_{\mathrm{L}, \mathrm{Ca}}$ was modeled as follows:

$$
g_{\mathrm{L}, \mathrm{Ca}}=g_{\text {peak }, \mathrm{Ca}} m h \text {. }
$$

Here $g_{\mathrm{L}, \mathrm{Ca}}$ represents the maximal conductance per surface area. The variable $m$ is a voltage- and time-dependent activation variable that is described by the differential equation:

$$
\frac{d m}{d t}=\frac{m_{\infty}-m}{\tau_{\mathrm{m}}}
$$

where the time constant of activation, $\tau_{\mathrm{m}}$, was assigned a value of $20 \mathrm{~ms}$ (Carlin et al., 2000). The steady-state activation level, $m_{\infty}$, is given by the following:

$$
m_{\infty}=\frac{1}{1+e^{\left(V_{\mathrm{m}}-V_{1 / 2}\right) / k}}
$$

where the half-activation voltage, $V_{1 / 2}$, was $-20 \mathrm{mV}$, a value intermediary to the half-activation voltage of the low-voltage-activated and highvoltage-activated currents described by Carlin et al. (2000). The activation sensitivity, $k$, was assigned a value of $-6 \mathrm{mV}$ (Carlin et al., 2000).

A slow calcium-dependent inactivation process is represented by the variable $h$ and described by the differential equation:

$$
\frac{d h}{d t}=\frac{h_{\infty}-h}{\tau_{\mathrm{h}}},
$$

where the time constant of activation, $\tau_{\mathrm{h}}$, was assigned a value of $3 \mathrm{~s}$ to approximate the inactivation timescale seen in our recordings. The steady-state activation level, $h_{\infty}$, is given by the following: 
Table 1. Geometry of motoneuron models (with similar dendrites) for voltage-clamp simulations

\begin{tabular}{|c|c|c|c|c|c|c|c|c|c|}
\hline \multirow[b]{2}{*}{ Model } & \multicolumn{3}{|l|}{ Proximal } & \multicolumn{3}{|l|}{ Medial } & \multicolumn{3}{|l|}{ Distal } \\
\hline & $\begin{array}{l}\text { Diameter } \\
(\mu \mathrm{m})\end{array}$ & $\begin{array}{l}\text { Length }^{a} \\
(\mu \mathrm{m})\end{array}$ & $\begin{array}{l}\text { Cav } 1.3 \text { density } \\
\left(\mathrm{mS} / \mathrm{cm}^{2}\right)\end{array}$ & $\begin{array}{l}\text { Diameter } \\
(\mu \mathrm{m})\end{array}$ & $\begin{array}{l}\text { Length }^{a} \\
(\mu \mathrm{m})\end{array}$ & $\begin{array}{l}\text { Ca } 1.3 \text { density } \\
\left(\mathrm{mS} / \mathrm{cm}^{2}\right)\end{array}$ & $\begin{array}{l}\text { Diameter } \\
(\mu \mathrm{m})\end{array}$ & $\begin{array}{l}\text { Length }^{a} \\
(\mu \mathrm{m})\end{array}$ & $\begin{array}{l}C a_{V} 1.3 \text { density } \\
\left(\mathrm{mS} / \mathrm{cm}^{2}\right)\end{array}$ \\
\hline$A$ & 3 & $100(0.08)$ & 0 & 2 & $100(0.10)$ & 0 & 1.0 & $200(0.10)$ & 0 \\
\hline $\mathrm{Ca}^{2+}$-dendrite1 & 3 & $200(0.16)$ & 0 & 1.5 & $100(0.11)$ & 1.75 & 1.0 & $200(0.10)$ & 0 \\
\hline $\mathrm{Ca}^{2+}$-dendrite2 & 3 & $200(0.16)$ & 0 & 1.5 & $100(0.11)$ & 1.75 & 1.0 & $200(0.10)$ & 0 \\
\hline$B$ & 3 & $100(0.08)$ & 0 & 2 & $100(0.10)$ & 0 & 1.0 & $200(0.10)$ & 0 \\
\hline $\mathrm{Ca}^{2+}$-dendrite1 & 3 & $200(0.16)$ & 0 & 1.5 & $100(0.11)$ & 2.00 & 1.0 & $200(0.10)$ & 0 \\
\hline $\mathrm{Ca}^{2+}$-dendrite2 & 2.5 & $500(0.43)$ & 0 & 1.5 & $100(0.11)$ & 2.00 & 1.0 & $200(0.10)$ & 0 \\
\hline$C$ & 3 & $100(0.08)$ & 0 & 2 & $100(0.10)$ & 0 & 1.0 & $200(0.10)$ & 0 \\
\hline $\mathrm{Ca}^{2+}$-dendrite 1 & 2.5 & $300(0.26)$ & 0 & 1.5 & $100(0.11)$ & 3.00 & 1.0 & $200(0.10)$ & 0 \\
\hline $\mathrm{Ca}^{2+}$-dendrite2 & 2.5 & $300(0.26)$ & 0 & 1.5 & $100(0.11)$ & 1.50 & 1.0 & $200(0.10)$ & 0 \\
\hline$D$ & 3 & $100(0.08)$ & 0 & 2 & $100(0.10)$ & 0 & 1.0 & $200(0.10)$ & 0 \\
\hline $\mathrm{Ca}^{2+}$-dendrite1 & 3 & $200(0.16)$ & 0.35 & 1.5 & $100(0.11)$ & 0.35 & 1.0 & $200(0.10)$ & 0.70 \\
\hline $\mathrm{Ca}^{2+}$-dendrite2 & 3 & $200(0.16)$ & 0.35 & 1.5 & $100(0.11)$ & 0.35 & 1.0 & $200(0.10)$ & 0.35 \\
\hline 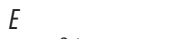 & 3 & $100(0.08)$ & 0 & 2 & $100(0.10)$ & 0 & 1.0 & $200(0.10)$ & 0 \\
\hline $\mathrm{Ca}^{2+}$-dendrite1 & 3 & $200(0.16)$ & 0 & 1.5 & $100(0.11)$ & 4 & 1.0 & $200(0.10)$ & 0 \\
\hline $\mathrm{Ca}^{2+}$-dendrite2 & 2.5 & $300(0.26)$ & 0 & 1.5 & $100(0.11)$ & 1.4 & 1.0 & $200(0.10)$ & 0 \\
\hline $\mathrm{Ca}^{2+}$-dendrite 2 & 2 & $600(0.58)$ & 0 & 1.5 & $100(0.11)$ & 1.2 & 1.0 & $200(0.10)$ & 0 \\
\hline$F$ & 3 & $100(0.08)$ & 0 & 2 & $100(0.10)$ & 0 & 1.0 & $200(0.10)$ & 0 \\
\hline $\mathrm{Ca}^{2+}$-dendrite1 & 2.5 & $400(0.35)$ & 0 & 1.5 & $100(0.11)$ & 1.50 & 1.0 & $200(0.10)$ & 0 \\
\hline $\mathrm{Ca}^{2+}$-dendrite2 & 1.75 & $600(0.62)$ & 0 & 1.5 & $100(0.11)$ & 0.50 & 1.0 & $200(0.10)$ & 0 \\
\hline$G$ & 3 & $100(0.08)$ & 0 & 2 & $100(0.10)$ & 0 & 1.0 & $200(0.10)$ & 0 \\
\hline $\mathrm{Ca}^{2+}$-dendrite1 & 3 & $200(0.16)$ & 0.19 & 1.5 & $100(0.11)$ & 0.19 & 1.0 & $200(0.10)$ & 0.19 \\
\hline $\mathrm{Ca}^{2+}$-dendrite2 & 3 & $200(0.16)$ & 0.03 & 1.5 & $100(0.11)$ & 0.03 & 1.0 & $200(0.10)$ & 0.03 \\
\hline$H$ & 3 & $100(0.08)$ & 0 & 2 & $100(0.10)$ & 0 & 1.0 & $200(0.10)$ & 0 \\
\hline $\mathrm{Ca}^{2+}$-dendrite1 & 2.5 & $400(0.35)$ & 0 & 1.5 & $100(0.11)$ & 1.50 & 1.0 & $200(0.10)$ & 0 \\
\hline $\mathrm{Ca}^{2+}$-dendrite 2 & 1.75 & $600(0.62)$ & 0 & 1.5 & $100(0.11)$ & 0.40 & 1.0 & $200(0.10)$ & 0 \\
\hline
\end{tabular}

Diameter, length, and $\mathrm{Ca}_{\mathrm{v}} 1.3$ conductance density for dendrites without $\mathrm{Ca}^{2+}$ conductances and for the two dendrites with $\mathrm{Ca}^{2+}$ conductances. $A$, Model with two equidense clusters, equidistant from the soma (voltage-clamp simulations); $B$, model with two equidense clusters at different distances from the soma (voltage-clamp simulations); $C$, model with two clusters of different densities, equidistant from the soma (voltage-clamp simulations); $D$, model with channels distributed in all compartments of two dendrites (voltage-clamp simulations); $E$, model with three clusters distributed in three dendrites (voltage-clamp simulations); $F$, model with two clusters (current-clamp simulations); $G$, model with channels distributed in all compartments of two dendrites (current-clamp simulations); $\mathrm{H}$, model with two clusters distributed in two dendrites and one cluster at the soma ( $\mathrm{Ca}_{\mathrm{v}} 1.3 \mathrm{density}$ of $0.06 \mathrm{mS} / \mathrm{cm}^{2}$ ) (current-clamp simulations). ${ }^{a}$ Electrotonic length in parentheses.

$$
h_{\infty}=\frac{K_{\mathrm{d}}}{\mathrm{Ca}+K_{\mathrm{d}}}
$$

where $\mathrm{Ca}$ is the internal calcium concentration, and $K_{\mathrm{d}}$, the halfsaturation level, was $0.1 \mu \mathrm{M}$. $E_{\text {rev }}$ for the calcium current was set at $60 \mathrm{mV}$ (Carlin et al., 2000).

Calcium diffusion was modeled according to the following equation (Booth et al., 1997):

$$
\frac{d}{d t} \mathrm{Ca}=f \times\left(-\alpha \times I_{\mathrm{Ca}}-k_{\mathrm{Ca}} \times \mathrm{Ca}\right),
$$

where $f$ describes the percentage of free to total $\mathrm{Ca}^{2+}$ and was set to 0.01 . The parameter $\alpha$, which was set to $0.9 \mathrm{mmol} \cdot \mu \mathrm{m}^{-1} \cdot \mathrm{C}^{-1}$, describes the rate at which the total $\mathrm{Ca}^{2+}$ current, $I_{\mathrm{Ca}}$, is converted to $\mathrm{Ca}^{2+}$ concentration, and the $\mathrm{Ca}^{2+}$ removal rate is defined by $k_{\mathrm{Ca}}$, which was set to 2 $\mathrm{ms}^{-1}$.

Simulations were performed using the NEURON (Yale University, New Haven, CT) simulation program. For the voltage-clamp simulations, the voltage-clamp electrode was modeled as a SEClamp point process, which is an ideal voltage source in series with a resistance. The value of the series resistance was $1 \mathrm{M} \Omega$.

\section{Results}

\section{Recordings from spinal motoneurons in slice}

Data were collected from a total of 22 mouse motoneurons in lumbar spinal cord slices. Consistent with the large size of these cells, the average whole-cell capacitance was $229 \pm 87 \mathrm{pF}$ ( \pm SD; range, $105-465 \mathrm{pF})$, and the input resistance was $169 \pm 145 \mathrm{M} \Omega$.

\section{Plateau potentials}

The activation of dendritic persistent inward currents in motoneurons can lead to the production of electrical events known as plateau potentials (Schwindt and Crill, 1980; Hounsgaard and
Kiehn, 1993; Lee and Heckman, 1996; Bennett et al., 1998). We first investigated whether calcium-dependent plateau potentials could be produced by mouse motoneurons. In current-clamp recordings using solutions that blocked sodium and potassium conductances, stimulation of motoneurons with rectangular depolarizing current pulses evoked "all-or-none" plateau potentials $(n=5)$ (Fig. $1 A)$. The regenerative plateaus were seen to slowly inactivate but could last for tens of seconds. This type of calcium plateau is similar to that shown to underlie plateau potentials in turtle spinal motoneurons (Hounsgaard and Kiehn, 1985). As in those cells, a sufficiently large hyperpolarizing current pulse was able to terminate the plateau (Fig. $1 B$ ). However, we now demonstrate that, in mouse motoneurons, smaller hyperpolarizing pulses were able to reduce the plateau potentials to intermediate levels $(n=4)$ (Fig. $1 C)$. In three of these neurons, repolarization to this intermediate potential occurred spontaneously (Fig. 1D). These data demonstrate two important aspects of mouse spinal motoneurons: (1) these cells possess the conductances capable of sustaining plateau potentials; and (2) these plateau potentials could be graded. The appearance of grading suggests that the underlying conductances do not function collectively in an allor-nothing manner. We hypothesized that the graded reduction in the amplitude of the plateau results from the deactivation of a subpopulation of activated channel clusters that are spatially separated from the channels that remain in the activated state.

\section{Staircase current waveform}

To provide better temporal separation of the currents underlying the graded plateau responses seen in current-clamp recordings, we proceeded with somatic voltage-clamp experiments, in which a somatically applied voltage command would lead to a voltage 


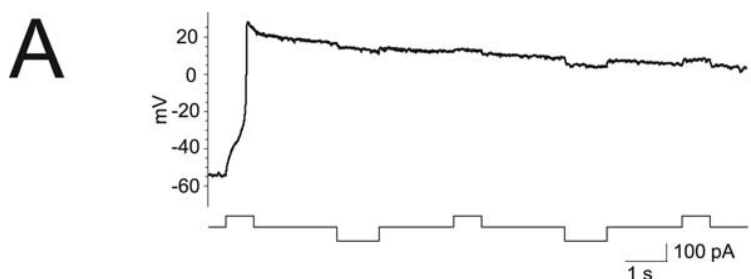

B

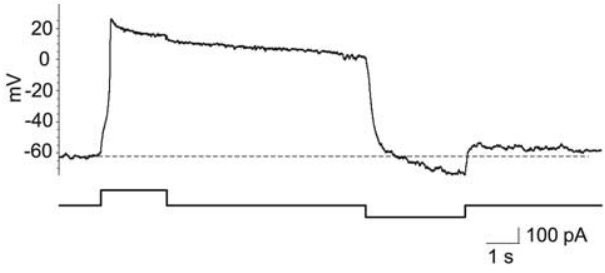

C

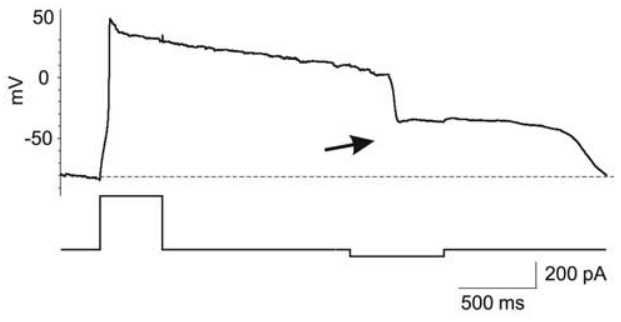

D

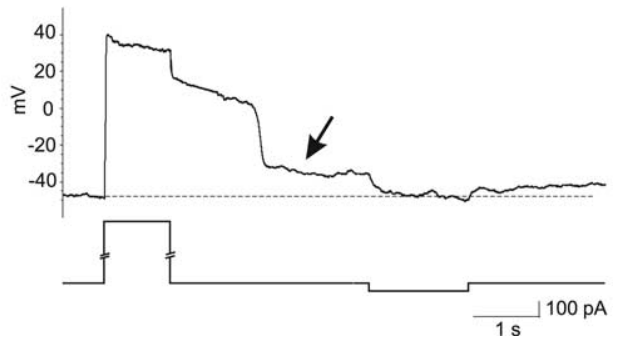

Figure 1. Plateau potentials in mouse spinal motoneurons can be partially deactivated. $\boldsymbol{A}$ Current-clamp recording of a plateau potential activated by a depolarizing somatic current step. The injected current is shown below the voltage recording. Note the persistence of the plateau potential despite the injection of hyperpolarizing current pulses. $\boldsymbol{B}$, Current-clamp recording of a plateau potential that is inactivated by a sufficiently large hyperpolarizing current step. Same motoneuron as in $\boldsymbol{A}$. Black dashed line marks the resting membrane potential. $\boldsymbol{C}$, Partial deactivation of the plateau potential by a hyperpolarizing current step. Black dashed line marks the resting membrane potential. Arrow denotes partial plateau. $\boldsymbol{D}$, Partial deactivation of the plateau potential in staircase-like manner in the absence of a hyperpolarizing current step. Black dashed line marks the resting membrane potential. Arrow denotes partial plateau.

gradient across the dendritic tree. This poor spatial control of motoneuron dendrites (Müller and Lux, 1993) leads to delays in the onset of inward currents originating from the dendrites (Booth et al., 1997; Carlin et al., 2000). Under voltage-clamp conditions, long-duration depolarizing commands resulted in multiple discrete late-onset currents, giving the current recording the appearance of a staircase $(n=16)$ (Fig. $2 A)$. A staircase current waveform was defined as one in which two or more discrete inward current deflections were elicited by a single voltage step command. The first stair current in the waveform was defined as the first inward current with an obvious delay from the initiation of the voltage step command. Staircase current waveforms were rarely seen using step commands in $10 \mathrm{mV}$ increments. We therefore typically investigated their occurrence using $500 \mathrm{~ms}$ commands in $2 \mathrm{mV}$ increments $(n=11)$. This ensured that the command would be close to the threshold [or saddle-node (Booth et al., 1997)], which would lead to resolvable activations of channel clusters (Booth et al., 1997; Carlin et al., 2000). The appearance of multiple stairs in the current trace is consistent with the hy-
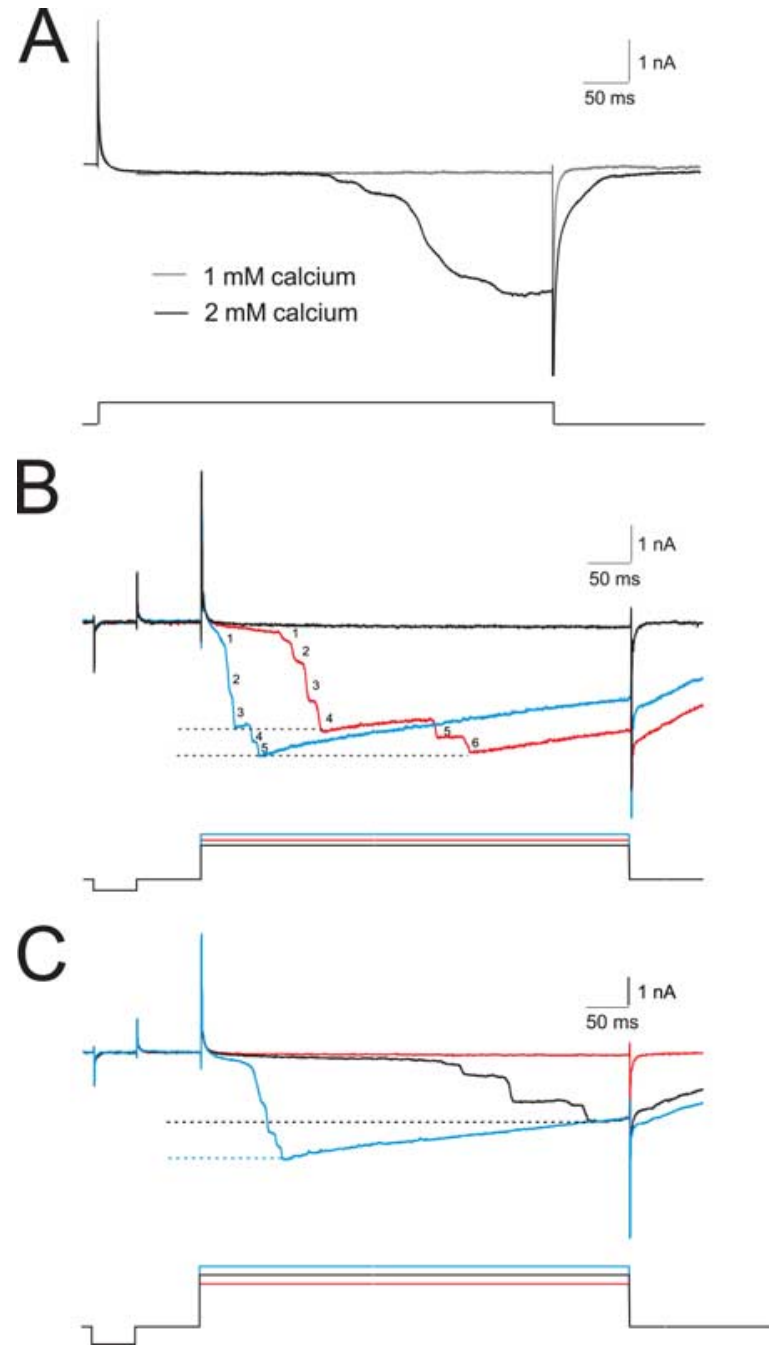

Figure 2. Staircase-like inward currents are seen in voltage-clamp recordings of spinal motoneurons. A, Staircase-like inward currents in response to depolarizing somatic voltage-clamp steps. Stairs are not seen in $1 \mathrm{~mm}$ extracellular calcium but are evident when the extracellular calcium concentration is increased to $2 \mathrm{~mm}$. Holding potential was $-60 \mathrm{mV}$. Voltage-clamp steps are illustrated below the recording (modified from Heckman et al., 2003, their Box 2, Fig. 1b). $\boldsymbol{B}$, Staircase currents of similar peak magnitudes in response to two different voltage-clamp steps with different numbers of stairs. Each individual stair is numbered. Voltage-clamp steps are illustrated below recording. Top dashed line shows similar amplitudes of first four red steps and first three blue steps. Bottom dashed line shows similar peak amplitudes. C, Staircase currents of increasing peak magnitude in response to increasing voltage-clamp steps. Dashed lines indicate peak amplitudes. The first step command was to $-25 \mathrm{mV}(\boldsymbol{B})$ or $-30 \mathrm{mV}(\boldsymbol{C}$, with subsequent steps increasing in $5 \mathrm{mV}$ increments.

pothesis that these currents arise from discrete current sources. The delay in the activation of an inward current suggests a source of $\mathrm{Ca}^{2+}$ current that is spatially remote from the recording electrode, in this case the cell body (Müller and Lux, 1993; Carlin et al., 2000).

To confirm that the staircase currents were mediated by voltage-gated calcium currents, experiments were repeated in different concentrations of external calcium. Increasing the calcium concentration to above $1 \mathrm{~mm}$ led to a staircase waveform, which was not detected when the same stimulation protocol was applied in the presence of lower concentrations $(n=9)$ (Fig. $2 A)$. Given that the single delayed-onset currents demonstrated under these conditions are mediated primarily by $\mathrm{Ca}_{\mathrm{V}} 1$-type channels (Carlin et al., 2000), we suggest that these channels likely also mediate the multiple stair currents seen in the present study. 

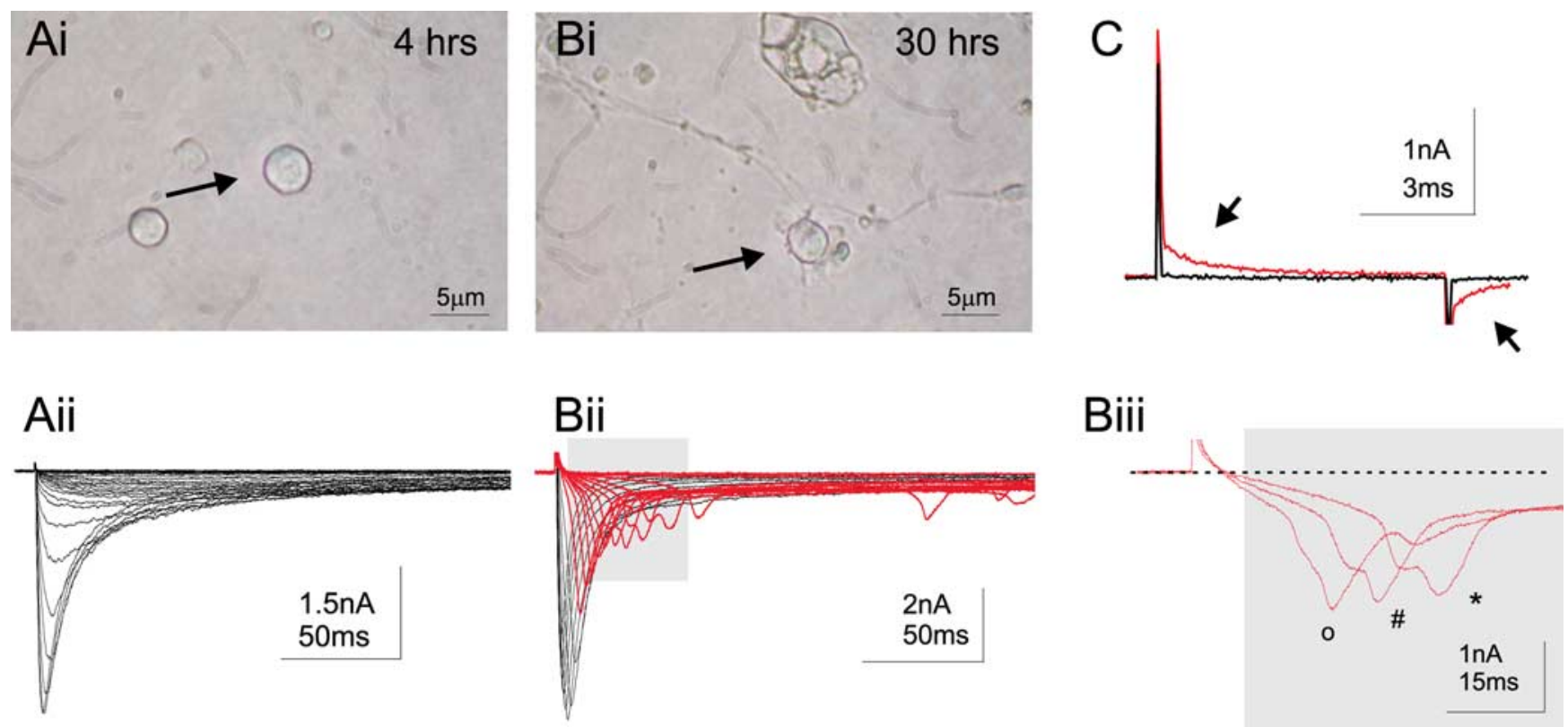

Figure 3. Staircase-like inward currents are seen in voltage-clamp recordings of cultured dorsal root ganglion cells. Ai, Photomicrograph of DRG neurons $4 \mathrm{~h}$ after plating. Note the absence of processes on these cells. Arrow indicates cell from which inward currents illustrated in Ai were recorded. Aii, Family of well-clamped inward currents recorded in response to $4 \mathrm{mV}$ incremental voltage steps. (holding potential, $-80 \mathrm{mV}$; cell capacitance, $12 \mathrm{pF}$; series resistance, $2.0 \mathrm{M} \Omega$ ). Bi, Photomicrograph of a DRG neuron from the same culture after $30 \mathrm{~h}$. Note the extensive processes this cell has developed. Bii, The current responses from a series of $6 \mathrm{mV}$ depolarizations demonstrate a number of late-onset inward currents. Traces with late-onset currents are illustrated in red (holding potential, $-80 \mathrm{mV}$; cell capacitance, $28 \mathrm{pF}$; series resistance, $1.3 \mathrm{M} \Omega$ ). Late-onset currents were evoked before the larger somatic currents (black traces). Biii, Three current traces taken from the gray area in Bi shown on expanded voltage and timescales. As seen in motoneurons, activation of multiple late-onset currents can show temporal overlap and appear as a staircase current. In response to increasing voltage steps, these currents respond with shorter delay as in motoneurons [current responses to voltage steps to $-42 \mathrm{mV}(*),-48 \mathrm{mV}(\#)$, and $-54 \mathrm{mV}(\bigcirc)$ from a holding potential of $-80 \mathrm{mV}$; dashed line is 0 current]. C, Capacitive transients for the cells illustrated in $\boldsymbol{A i}$ (black) and $\boldsymbol{B i}$ (red) elicited by $10 \mathrm{mV}$ subthreshold voltage steps (holding potential, $-80 \mathrm{mV}$ ). Consistent with the presence of processes (extrasomatic membrane) on the cell in $\boldsymbol{B}$, the decay of the capacitive current has an addition slow component that is not present in the cell in $\boldsymbol{A i}$ (arrows).

\section{Characteristics of staircase currents}

The presence of a delay to onset of the first inward current suggests a source of $\mathrm{Ca}^{2+}$ current spatially removed from the recording electrode, in this case the cell body (Müller and Lux, 1993; Carlin et al., 2000). The maximum number of stair currents elicited varied across the population of motoneurons. The median number was three with a range of two to six. In 15 of 16 motoneurons, the maximum number of stairs was elicited at the first step at which a staircase was produced. In one of the motoneurons, the maximum number of stairs was elicited at the subsequent step after the generation of the first staircase current.

The mean somatic voltage to activate the staircase current with the maximal number of stairs was $-27 \pm 9 \mathrm{mV}$, and the delay to the onset of the first stair in the series was $83 \pm 64 \mathrm{~ms}$. As shown previously by Carlin et al. (2000), in all cells tested, increasingly depolarized voltage steps resulted in the first inward current being activated with shorter delay (Fig. $2 B, C$ ), indicating a reduced time-to-threshold with a larger amplitude voltage step applied to the soma. Furthermore, the number of stairs typically decreased with each subsequent depolarizing voltage-clamp step, ultimately leading to a single-sloped inward current. The observed decrease in the number of stairs once the maximum number was reached raised the possibility that multiple stairs could merge into single steps. In Figure $2 B$, two staircase currents are elicited with different voltage steps. Although both staircase currents reach the same peak inward current, they do so with different number of stairs. The first staircase current is composed of six stairs (red 1-6), whereas the staircase current produced with the next incremental voltage command is composed of five stairs (blue 1-5). The last two stairs of each staircase currents (red 5, 6 and blue 4,5 ) are similar in amplitude, suggesting that the first four stairs of the earlier staircase (red 1-4) merged to generate three stairs in the later staircase (blue 1-3). This indicates that weak depolarizations are more likely to temporally disperse the activation of each current source, thus leading to a staircase current. By shortening the delay of each stair, stronger depolarizations lead to their apparent synchronous activation and a seemingly single-sloped inward current. This suggests that the larger depolarizing steps lead to the simultaneous activation of more than one conductance source.

\section{Staircase currents in cultured dorsal root ganglion neurons}

One of the possible interpretations of the data presented above is that the currents underlying the individual stairs originate at different locations in the dendritic tree. To provide additional evidence that these multiple inward currents resulted from dendritic conductances, we used an in vitro model in which the presence or absence of distal inward conductances could be better controlled. We selected a simpler biological model, dissociated DRG neurons in short-term culture, in which the generation of staircase currents in the presence and absence of neurites and their associated voltage-gated conductances could be assessed. These neurons express voltage-gated sodium channels (Gottmann et al., 1988), and, within $12-24 \mathrm{~h}$ of undergoing dissociation and plating, the cells extend processes that express voltage-gated sodium channels (Gottmann et al., 1991). During the dissociation procedure, DRG cell bodies are stripped of their axons and therefore initially have no processes (Fig. 3Ai). Under these conditions, late-onset currents were not seen $(n>100)$ (Fig. 3Aii). However, by the second day in culture, the development of processes is obvious (Fig. 3Bi) and the presence of the extended membrane can be detected in the capacitive transient as a slowly charging and discharging 
component (Fig. 3C). Once processes developed, both late-onset and staircase currents were recorded (Fig. 3 Bii,Biii). As in spinal motoneurons, increasing the amplitude of the voltage command elicited late-onset currents with shorter delays, which merged into a single inward current with larger voltage commands $(n=7$ cells) (Fig. 3Bii). These data reinforce the idea that extended neuritic processes and the spatially segregated channels they contain are necessary for the generation of staircase currents. These results are consistent with the hypothesis that, in motoneurons, staircase currents are generated by currents distributed in extended processes.

\section{Staircases in motoneuron models}

The results from the DRG cell culture experiments strengthen the possibility that the staircase currents observed in motoneurons could be generated from voltage-gated calcium conductances located in multiple spatially segregated portions of the dendritic tree. However, they do not give us any additional insights into the distribution of these active conductances that generate staircase currents. To explore the possible distributions that may generate the staircase currents recorded in motoneurons, we used mathematical models in which the contribution of geometry and the distribution of active conductances to the production of staircase currents could be assessed.

\section{Symmetry versus asymmetry}

The staircase waveform suggests a sequential recruitment of multiple inward current sources that converge to depolarize the cell body in which the recording electrode is located. The fact that the individual stairs are recruited at different times suggests some aspect of spatial asymmetry in their distribution. Several studies have suggested that $\mathrm{Ca}_{\mathrm{V}} 1.3$ channels are localized in clusters distributed at varying distances from the cell body (Carlin et al., 2000; Bui et al., 2006; Elbasiouny et al., 2006; Grande et al., 2007a). Therefore, we generated compartmental models consisting of a soma and seven three-compartment primary dendrites, only two of which contained clusters of $\mathrm{Ca}_{\mathrm{V}} 1.3$ channels (Fig. 4).

In the first model, the channels were located in the middle of the three compartments and were distributed at the same density in both dendritic trees. The current response to a somatic voltage-clamp step did not exhibit more than one delayed current (Fig. 4A). We therefore generated asymmetry in the model by changing the length of one of the primary branches (proximal to the channel clusters), effectively increasing the distance of one of the $\mathrm{Ca}_{\mathrm{V}} 1.3$ channel clusters from the cell body. The densities of both clusters were adjusted to generate approximately the same peak inward current. These asymmetric distances led to a twostair current waveform in response to somatic voltage clamp (Fig. $4 B$ ). In this model, the membrane potential of the two middle compartments exhibited a single phase (i.e., no stairs). However, the cluster of channels that was located closer to the cell body was activated at a shorter delay than the cluster of channels that was located at a greater distance to the cell body in the other primary dendrite (Fig. $4 B$, dashed lines). This difference in the delay to activation led to the appearance of a two-stair waveform of the current measured in the somatic compartment. As the voltageclamp depolarization increased, the delay to onset of the first stair current shortened, and both clusters were activated synchronously, leading to a single-sloped inward current (Fig. $4 \mathrm{~B}$, purple or black traces). Therefore, we could reproduce the staircase current recorded experimentally using a model with asymmetrically distributed clusters of $\mathrm{Ca}_{\mathrm{V}} 1.3$ channels.

To test the effect of asymmetry produced by varying cluster

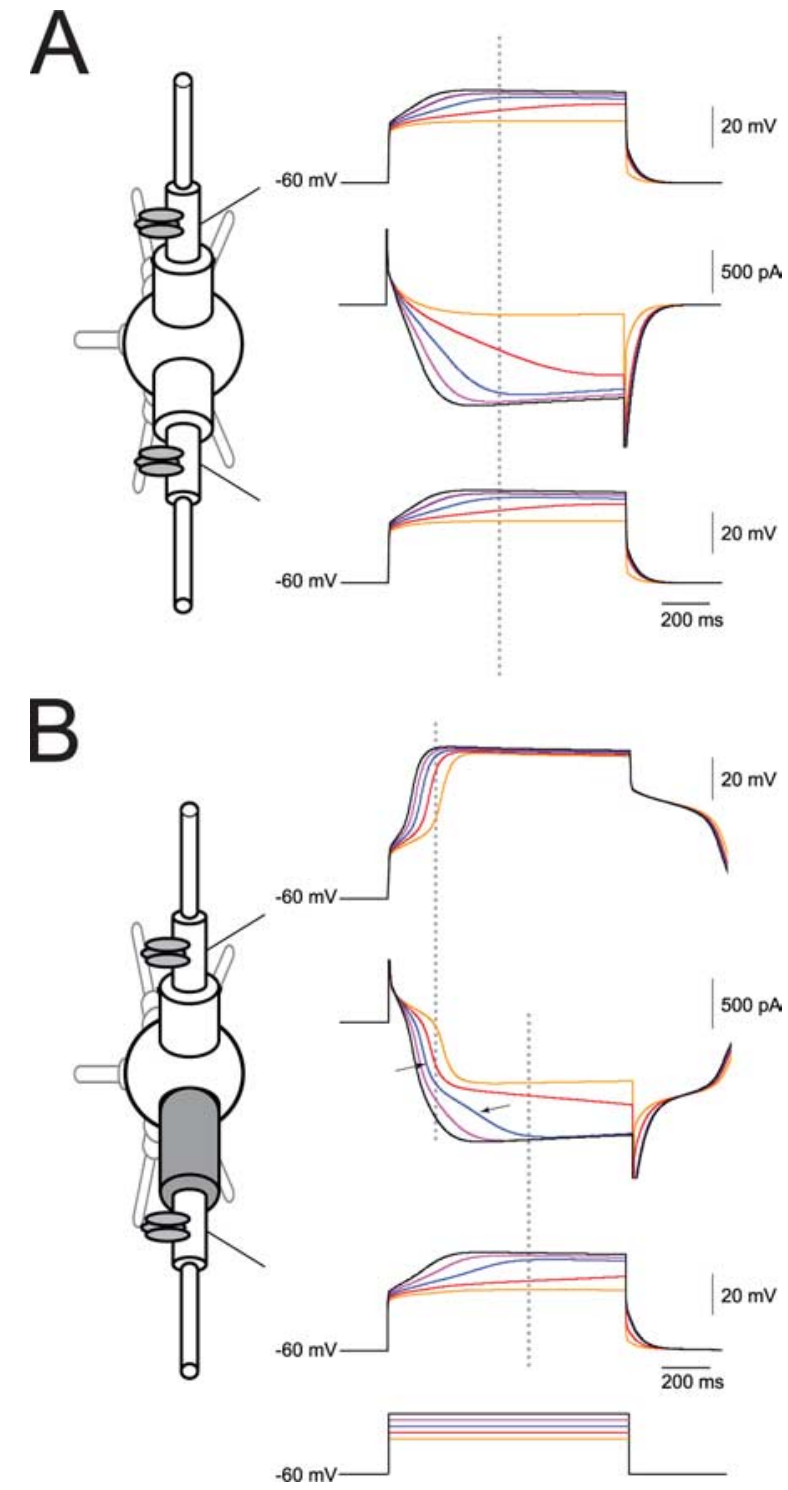

Figure 4. Simulations of staircase-like inward current in multicompartmental motoneuron model. $A$, Model with two clusters of equal number of $\mathrm{Ca}_{\mathrm{v}} 1.3$ channels and equidistant from the cell body. $\boldsymbol{B}$, Model with two clusters of equal number of $\mathrm{Ca}_{\mathrm{v}} 1.3$ channels located at different distances from the cell body. The time to plateau is different for the two dendritic compartments with $C a_{y} 1.3$ channels leading to the staircase current. Arrows mark stairs in blue traces in each figure. $\boldsymbol{A}, \boldsymbol{B}$, Right, top and bottom, Membrane potential at dendritic compartments with $\mathrm{Ca}_{\mathrm{v}} 1.3$ channels. Right, middle, Somatic voltage-clamp current. Dashed lines indicate time-to-peak of the blue traces in the dendritic membrane potential recordings. For $\boldsymbol{A}$, the voltage-clamp step commands range from -33 to $-29 \mathrm{mV}$. For $\boldsymbol{B}$, the voltage-clamp step commands range from -35 to $-30 \mathrm{mV}$.

properties (for example, the density) as opposed to cluster distance, we next used a model with $\mathrm{Ca}_{\mathrm{V}} 1.3$ clusters of different densities located at similar distances. This model also generated a staircase current (Fig. 5A). In addition, it was determined that the model did not require the channels to be clustered to generate a staircase waveform, as long as some aspect of asymmetry was present. As seen in Figure $5 B$, a model with $\mathrm{Ca}_{\mathrm{V}} 1.3$ channels distributed in every compartment of identical dendrites, as well as the soma, but with different densities in one (e.g., the most distal) compartment could also generate a staircase waveform. Thus, the sequential activation of multiple inward current sources requires differences in the excitability of each current source. This difference in excitability could result 


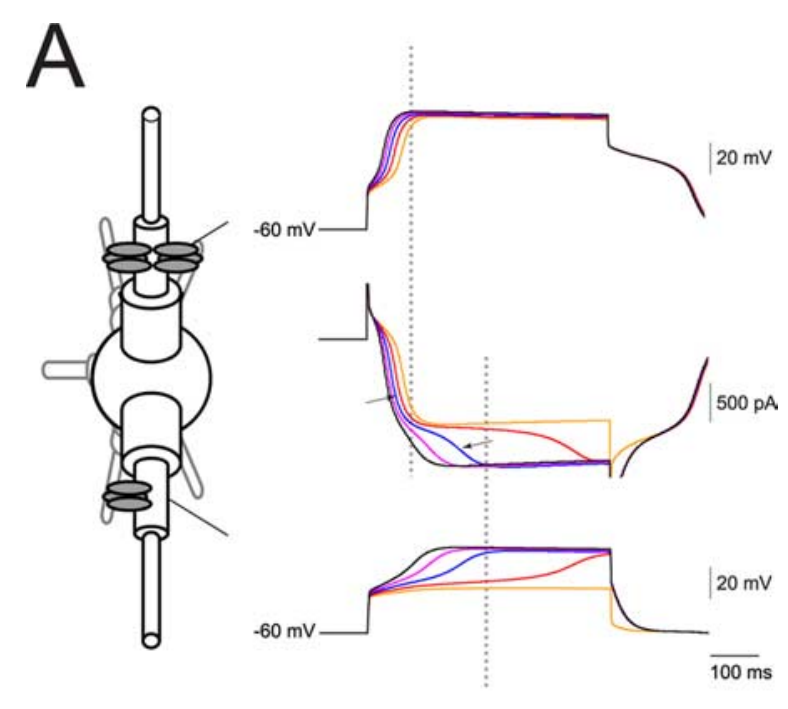

B

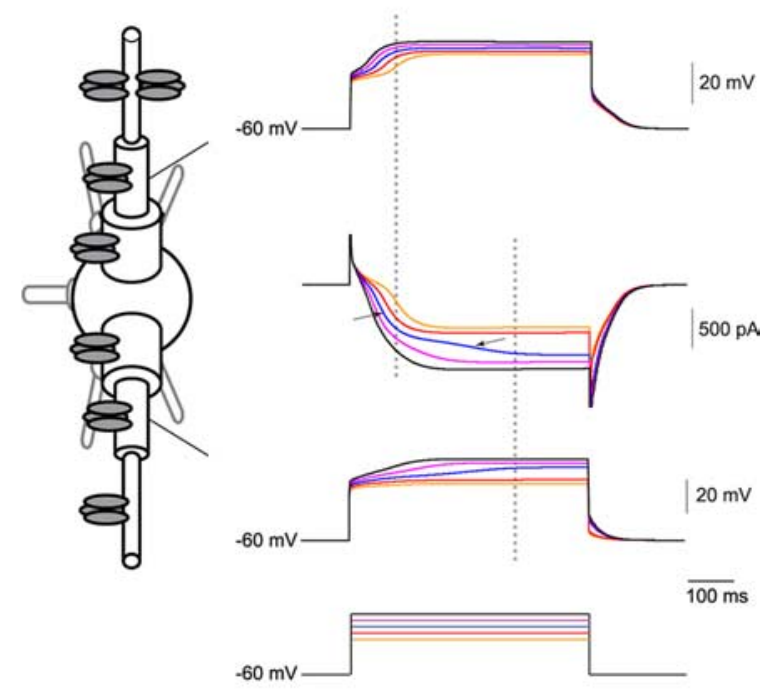

C
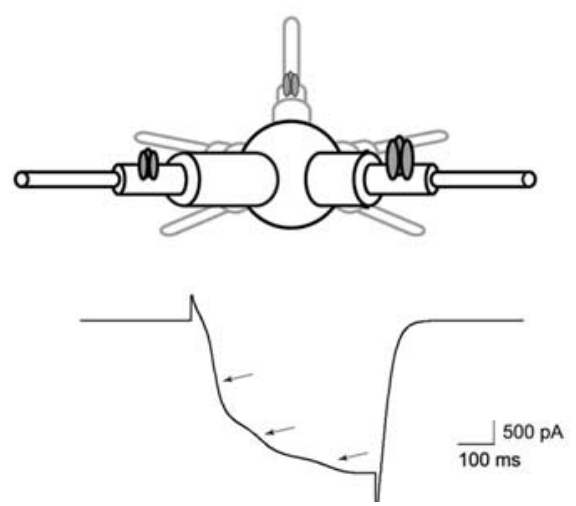

Figure 5. Simulations of staircase-like inward current in multicompartmental motoneuron model with asymmetric distribution of $C a_{v} 1.3$ channels. $\boldsymbol{A}$, Model with two $C a_{v} 1.3$ channel clusters differing in density; both clusters are equidistant from the cell body. $\boldsymbol{B}$, Model with clusters of $\mathrm{Ca}_{v} 1.3$ channels distributed in every compartment of the two active dendrites. The density of channels is the same in every compartment except for one of the two distal compartments in which the density was doubled. $\boldsymbol{A}, \boldsymbol{B}$, Right, top and bottom, Membrane potential at dendritic compartments with $\mathrm{C}_{\mathrm{v}} 1.3$ channels. Right, middle, Somatic voltage-clamp current Dashed lines indicate time-to-peak of the blue traces in the dendritic membrane potentia recordings. For both $\boldsymbol{A}$ and $\boldsymbol{B}$, the voltage-clamp step commands range from -36 to $-32 \mathrm{mV}$. C, Model with three active dendrites. Top, Graphical representation of the model. Bottom, Somatic voltage-clamp current in response to a step command from -60 to $-35 \mathrm{mV}$. from either a difference in the channel density of clusters or a difference in the electrotonic environment within which each current source resides.

Next, to confirm that more than two stairs could be modeled, we used a model with $\mathrm{Ca}_{\mathrm{V}} 1.3$ channel clusters of different densities and at different distances from the cell body in three dendrites (Fig. 5C). As expected, this model generated staircase currents with three stairs. These data demonstrate that our models are capable of replicating the basic components of the staircase waveform seen in our motoneuronal voltage-clamp experiments by asymmetrically distributing $\mathrm{Ca}_{\mathrm{V}} 1.3$ channels on a number of dendrites.

\section{Spatial separation of clusters}

Replication of the staircase currents observed in our voltageclamp experiments of motoneurons imposed the condition of asymmetry on the distribution of $\mathrm{Ca}_{\mathrm{V}} 1.3$ channels in the model. Next, we attempted to model the partial deactivation of plateau potentials by weak hyperpolarizing current injection that was observed in our current-clamp experiments (Fig. 1C,D) to define any additional constraints on the distribution of $\mathrm{Ca}_{\mathrm{v}} 1.3$ channels. Figure $6 \mathrm{~A}$ illustrates a model with two clusters of $\mathrm{Ca}_{\mathrm{V}} 1.3$ channels of different densities and located at different distances from the cell body that was able to generate a plateau potential that partially repolarized after a hyperpolarizing current stimulus (Fig. 6A). This partial bistability resulted from a difference in the level of deactivation of the two channel clusters in response to hyperpolarizing current (Fig. 6 Aiii). In this model, there was a greater amount of deactivation of the cluster located farther away from the cell body (red compartment) compared with the deactivation of the more proximal cluster (blue compartment). This relative difference in deactivation levels was sustained after cessation of the hyperpolarizing current and resulted in a partial deactivation of the plateau potential. Importantly, this model also generated staircase currents in response to somatic voltageclamp depolarization (Fig. 6 Aiv).

In contrast to the above model, models with clusters that were either closer to each other or had clusters with greater channel density than the model in Figure $6 \mathrm{~A}$ could not produce partially deactivating plateau potentials. The reason for this is illustrated in Figure $6 \mathrm{~B}$. Here, $\mathrm{Ca}_{\mathrm{v}} 1.3$ channels were located in all the compartments of the two dendrites. The density of $\mathrm{Ca}_{\mathrm{V}} 1.3$ channels is higher in one of the two dendrites. The densities were adjusted so that the size of the plateau potential was similar to that in Figure $6 \mathrm{~A}$. Despite the comparable size of the plateau potential, we could not partially deactivate the plateau potential by varying the amplitude of the current hyperpolarization (the response to hyperpolarizing steps of -10 and $-10.5 \mathrm{pA}$ are illustrated, but no partial deactivation could be generated by hyperpolarizing steps of magnitude intermediate to these two values). In response to hyperpolarizing current steps, the channels would either mutually reactivate each other after the end of the current step (Fig. 6 Biii, dashed lines) or completely deactivate in response to the hyperpolarizing current (Fig. 6 Biii, solid lines). A similar inability to partially deactivate plateau potentials was observed in a model in which the density of $\mathrm{Ca}_{\mathrm{V}} 1.3$ conductances was the same in all compartments of two dendrites except for a higher density in one of the two distal compartments (data not shown). This coupling between the two dendrites stems from the electrotonic proximity of both regions of $\mathrm{Ca}_{\mathrm{V}} 1.3$ channels, that is, the lack of independence of the dendritic compartments. Thus, the generation of partially deactivating plateau potentials requires sources of $\mathrm{Ca}_{\mathrm{V}} 1.3$ channels that are electrotonically separated. In the 
$\mathbf{A}_{\mathrm{i}}$

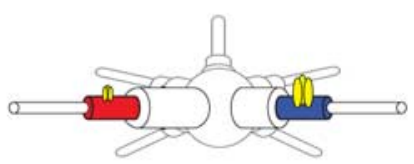

ii

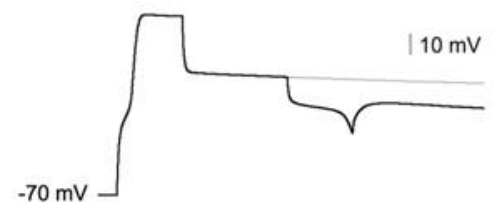

iii

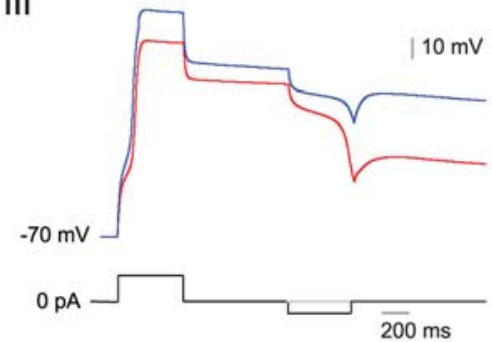

iv

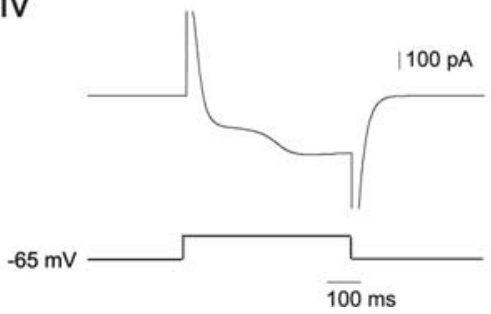

B.

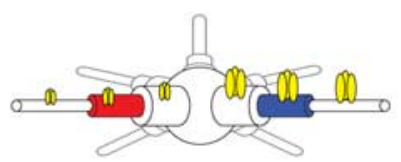

ii

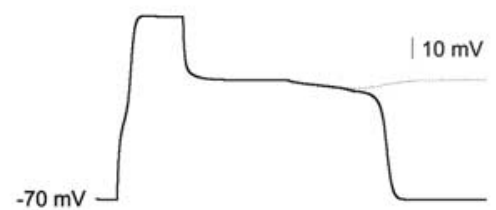

iii

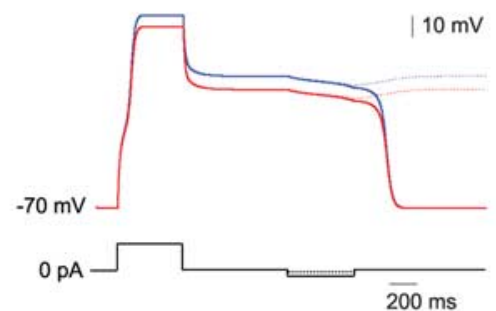

C.

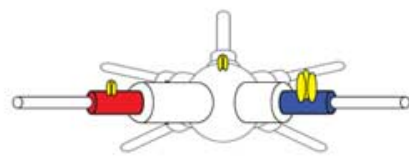

ii

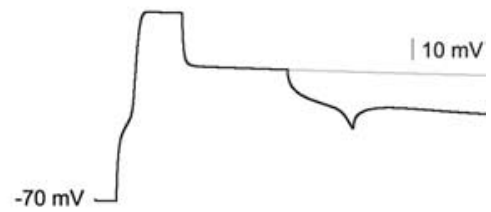

iii

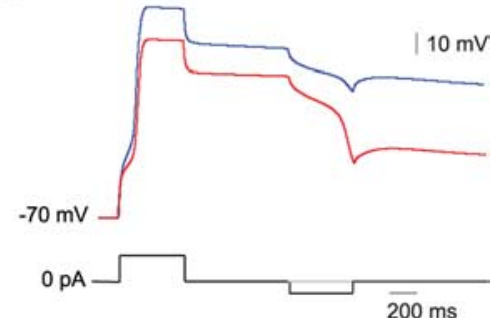

Figure 6. Simulations of the partial deactivation of plateau potentials during current-clamp recordings. $A$, Simulations with a model with two clusters of $\mathrm{Ca}_{v} 1.3$ channels located in two dendrites. Clusters are of different densities and are located at different distances from the cell body. $\boldsymbol{A i}$, Graphical representation of the model. Aii, Somatic membrane potential in response to stimulation protocol of a $500 \mathrm{~ms}, 500 \mathrm{pA}$ depolarizing step, followed by a $500 \mathrm{~ms}$, - 212 pA hyperpolarizing step (black trace) or no hyperpolarizing step (gray trace). Aiiii, Top, Dendritic membrane potential in response to stimulation protocol with a hyperpolarizing current step. Colors of traces correspond to colored compartments in graphical representation of the model. Only the responses to the stimulation protocol with an applied membrane hyperpolarization is shown. Bottom, Somatic current stimulation protocol. Aiv, Staircase current in response to voltage-clamp step of $-26 \mathrm{mV}$ applied at the soma. $\boldsymbol{B}$, Simulations with a model with $\mathrm{Ca}_{\mathrm{v}} 1.3$ channels located in all compartments of two dendrites. The density of channels is higher in one dendrite. $\boldsymbol{B i}$, Graphical representation of the model. Bii, Somatic membrane potential in response to stimulation protocol of a $500 \mathrm{~ms}, 500 \mathrm{pA} \mathrm{depolarizing} \mathrm{step,} \mathrm{followed} \mathrm{by} \mathrm{a} 500 \mathrm{~ms},-10 \mathrm{pA}$ hyperpolarizing step (black trace) or -10.5 pA (dashed trace). Biii, Top, Dendritic membrane potential in response to stimulation protocols. Colors of traces correspond to colored compartments in graphical representation of the model. Bottom, Somatic current stimulation protocol. C, Simulations with a model with three $\mathrm{Ca}_{\mathrm{v}} 1.3$ channel clusters, one located at the soma and two located in two different dendrites. $\mathrm{C}$, Graphical representation of the model. Cii, Somatic membrane potential in response to stimulation protocol of a $500 \mathrm{~ms}, 500$ pA depolarizing step, followed by a $500 \mathrm{~ms},-140 \mathrm{pA}$ hyperpolarizing step (black trace) or no hyperpolarizing step (gray trace). Ciii, Top, Dendritic membrane potential in response to stimulation protocol with a hyperpolarizing current step. Colors of traces correspond to colored compartments in graphical representation of the model. Bottom, Somatic current stimulation protocol.

model with two clusters of $\mathrm{Ca}^{2+}$ channels shown in Figure $6 \mathrm{~A}$, the minimal sum of the electrotonic distance from the soma of the two clusters that enabled the partial deactivation of a plateau potential was $0.97 \lambda$. However, the amount of separation required depends on the excitability of each source as determined in part by the density of channels. This is illustrated in our final model with three clusters of $\mathrm{Ca}_{\mathrm{V}} 1.3$ channels, one located at the soma (cf. Westenbroek et al., 1998; Simon et al., 2003; Zhang et al., 2008) and two located on two dendrites. Although the presence of somatic calcium channels reduced the spatial separation between sources of calcium current compared with the model of Figure $6 \mathrm{~A}$, the density of channels and the distance between the three clusters could be adjusted such that partially deactivating plateau potentials was produced (Fig. $6 \mathrm{C}$ ).

In summary, we demonstrate that, although asymmetry is required to generate the staircase currents seen during voltageclamp recordings in motoneurons, the partial deactivation of plateau potentials seen in the current-clamp recordings requires both asymmetry and a level of independence achieved by electrotonic separation of the $\mathrm{Ca}_{\mathrm{V}} 1.3$ channel clusters in different dendritic compartments.

\section{Discussion}

We have previously demonstrated voltage-gated calcium currents recorded from spinal motoneurons in slice preparations in which a portion of the dendritic tree remains intact (Carlin et al., 2000). In that paper, we argued that currents originating in the somata could be separated from those originating in more distal parts of the cells (i.e., dendritic tree) by using somatic voltageclamp commands. In the present paper, we present additional evidence for the presence of dendritically located voltage-gated calcium channels and argue that the channels underlying these inward dendritic currents are distributed in a spatially segregated manner in the dendritic tree. These conclusions stem from the partial 
deactivation of plateau potentials and the delayed stepwise activation of inward currents, which gives a staircase-like appearance to the current trace in response to the application of somatic voltage-clamp steps. A similar staircase can be seen in recordings of tail motoneurons of spinalized rats [Li and Bennett, (2003), see their Fig. 7A].

Recordings from dorsal root ganglion cells at different stages of development in culture were used to demonstrate that voltagegated conductances in processes arising from the cell body were sufficient for the presence of staircase waveforms, and computational models of motoneurons were then used to explore the spatial arrangement of channels required to produce the staircase waveform. The simulation experiments suggest that the staircase waveform arises from multiple dendritic calcium currents that are activated with varying delays by the somatic voltage command. The different delays in $\mathrm{Ca}_{\mathrm{V}} 1.3$ channel activation originated from distinct electrical conditions in each dendrite, through either different channel densities or different distances from the cell body. That is, an asymmetrical distribution of $\mathrm{Ca}_{\mathrm{V}} 1.3$ channels was necessary to produce the staircase waveform in voltage clamp. Thus, we conclude that $\mathrm{Ca}_{\mathrm{V}} 1.3$ channels are distributed in an asymmetric manner in the dendritic tree.

To relate this finding to the demonstration of partial deactivation of plateau potentials in response to membrane hyperpolarizations (Fig. 1), we studied whether there should be additional constraints on the distribution of $\mathrm{Ca}_{\mathrm{V}} 1.3$ channels. We found that, for a model to replicate both the staircase waveform in voltage clamp and the partial deactivation of the plateau potential in current clamp, it was necessary to have not only an asymmetric distribution but also spatial segregation of the channel clusters. Thus, data from our electrophysiological and modeling studies provide additional evidence for the presence of voltage-gated calcium channels on the dendrites of spinal motoneurons and suggest the likely spatial arrangement of these channels in the dendritic tree. These results indicate a necessity for (1) channels to be expressed on multiple dendrites, (2) channels to be arranged in clusters, (3) asymmetry between dendrites containing these channel clusters, and (4) segregation of the channel clusters so that they act independently.

Our electrophysiological and computational findings are in agreement with a previous study of neocortical pyramidal neurons that also linked the presence of stepwise events to a nonhomogeneous distribution of dendritic $\mathrm{Ca}^{2+}$ channels (Reuveni et al., 1993). Using computational models, stepwise repolarizations from $\mathrm{Ca}^{2+}$ plateaus in those neurons were attributed to the independent deactivation of L-type $\mathrm{Ca}^{2+}$ channels at electrotonically segregated "hot spots." Several computational studies using motoneuron models have come to a similar conclusion: functional $\mathrm{Ca}_{\mathrm{V}} 1.3$ channels in motoneurons are distributed in segregated regions of the dendritic tree (Bui et al., 2006; Elbasiouny et al., 2006; Grande et al., 2007a).

The distance required between clusters of $\mathrm{Ca}_{\mathrm{V}} 1.3$ channels will depend on the structure of each motoneuron as well as the presence of other conductances. In our experiments, potassium and sodium channels were blocked. The presence of potassium channels would allow clusters of channels to be closer to each other. Conversely, the presence of dendritic sodium channels in motoneurons (Jones and Lee, 2006) would necessitate a greater electrotonic separation between $\mathrm{Ca}_{\mathrm{V}} 1.3$ channel clusters than reported in our study.

\section{Other possible biophysical mechanisms}

It is possible that there are biophysical mechanisms that could lead to staircase currents and partially deactivated plateau poten- tials in motoneurons in the absence of asymmetry and spatial segregation of calcium channels in the dendrites. Recordings of nucleated patches from brainstem motoneurons indicated that calcium channels could operate in different states depending on the membrane potential (Moritz et al., 2007). In light of this evidence, the staircase waveforms that we observed could be produced by somatically distributed channels that are found in different states. Alternatively, different subpopulations of calcium channels in different states could be distributed asymmetrically across the soma. Another possibility is that different dendritic trees or compartments have different calcium dynamics (calcium release/calcium buffering), which would influence the velocity at which a calcium front propagates (Loewenstein and Sompolinsky, 2003). Although our data do not exclude any of these possibilities, they seem unlikely: the number of stairs that we report would require a delicate balance of at least six (the maximum number of stairs reported) different populations of channels operating in distinct activation states or six different regions with distinct calcium dynamics.

\section{Implications for synaptic integration in motoneurons}

Our data demonstrate activation of electrotonically segregated clusters of $\mathrm{Ca}_{\mathrm{V}} 1.3$ channels in motoneuronal dendrites. The presence of multiple clusters scattered across the dendritic tree presents a substrate for the compartmentalization of the dendritic tree. In such an arrangement, the operations of motoneurons could consist of the integration of independent computations performed by multiple compartments, with each compartment localized around a discrete region of $\mathrm{Ca}_{\mathrm{V}} 1.3$ channels. This computational arrangement is similar to the proposed organization in CA1 pyramidal neurons in which synaptic integration consists of the linear sum of the voltages resulting from nonlinear postsynaptic effects distributed throughout the dendrites (Poirazi et al., 2003a,b). As in pyramidal neurons (Poirazi and Mel, 2001), such compartmentalization would greatly increase the computational ability of motoneurons.

There are several reported instances of synaptic amplification in motoneurons that could result from a summation of PICs originating in separate compartments. Heckman and Lee (1999) discussed that amplification of primary afferent input during a plateau potential could increase the fraction of the dendritic tree in the "up" state. An alternate model of motoneurons with two modes of amplification (slow vs fast) implemented by two different sets of conductances also presents somewhat similar conclusions: the mechanisms underlying the two modes of amplification are spatially segregated in the dendrites (Shapiro and Lee, 2007). Prather et al. (2001) reported that the amplification of combined synaptic excitation to medial gastrocnemius motoneurons produced by stimulation of Ia afferents and sural caudal afferents together was approximately the algebraic sum of the amplification of each of the two synaptic inputs when stimulated alone. Hultborn et al. (2003) suggest that the mechanism underlying the graded amplification of corticospinal and of Ia afferent inputs to motoneurons is the activation of PICs that are located in the immediate proximity to the activated synapses. Together with our findings, these above findings would imply that these synaptic activations are in electrotonically distinct compartments of the dendritic trees and would explain how graded effects are seen in the soma in response to all-or-none effects in the dendrites.

The nonhomogeneous distribution of certain synaptic inputs to motoneurons further argues for compartmentalization of the dendritic tree. Delgado-Lezama et al. (1999) demonstrated that non-uniformly distributed metabotropic inputs to motoneurons 
can selectively restrict the activation of inward currents to particular regions of the dendritic tree. Grande et al. (2005) reported that synaptic inputs from descending vestibulospinal axons are distributed preferentially on the medial dendrites of neck motoneurons. A subsequent modeling study of this input demonstrated that both the asymmetric distribution of ligand-gated and $\mathrm{Ca}_{\mathrm{V}} 1.3$ conductances combined to preferentially strengthen what would otherwise be a weak set of synaptic inputs (Grande et al., $2007 \mathrm{~b}$ ). This is also demonstrated in studies of Renshaw cells. The distribution of synapses from Renshaw cells onto motoneurons has been shown to be primarily restricted to the proximal region of the dendritic tree ( $>93 \%$ of contacts are found between 65 and $465 \mu \mathrm{m}$ from the cell body) (Fyffe, 1991). A study of the deactivation of PICs by Renshaw cell inputs to motoneurons revealed that the superposition between $\mathrm{Ca}_{\mathrm{V}} 1.3$ channels and Renshaw cell synapses significantly increases the likelihood of deactivation of PICs by these inhibitory inputs (Bui et al., 2008b). There is therefore mounting evidence that the dendritic tree of motoneurons should be considered as a network of compartments defined by the distribution of voltage- and ligand-gated channels in the dendritic tree. We present evidence of spatial segregation of $\mathrm{Ca}_{\mathrm{V}} 1.3$ channels that would serve as an ideal substrate of such compartmentalization.

During the course of generating motor activity, motoneurons receive a multitude of synaptic inputs from multiple populations of spinal interneurons as well as from sensory and supraspinal sources. Motoneuron dendrites are endowed with voltageactivated currents that allow electrotonically distant synaptic currents to be seen at the spike-initiating zone. The data presented here indicate that the dendrites are electrically compartmentalized by the distribution of PICs. This compartmentalization would provide motoneurons with the ability to process multiple sources of input in parallel and integrate this processed information to produce appropriate trains of action potentials for the intended motor behavior.

\section{References}

Ballou EW, Smith WB, Anelli R, Heckman CJ (2006) Measuring dendritic distribution of membrane proteins. J Neurosci Methods 156:257-266.

Barrett JN, Crill WE (1974) Specific membrane properties of cat motoneurones. J Physiol 239:301-324.

Bennett DJ, Hultborn H, Fedirchuk B, Gorassini M (1998) Synaptic activation of plateaus in hindlimb motoneurons of decerebrate cats. J Neurophysiol 80:2023-2037.

Booth V, Rinzel J, Kiehn O (1997) Compartmental model of vertebrate motoneurons for $\mathrm{Ca}^{2+}$-dependent spiking and plateau potentials under pharmacological treatment. J Neurophysiol 78:3371-3385.

Brownstone RM, Gossard JP, Hultborn H (1994) Voltage-dependent excitation of motoneurones from spinal locomotor centres in the cat. Exp Brain Res 102:34-44.

Bui TV, Ter-Mikaelian M, Bedrossian D, Rose PK (2006) Computational estimation of the distribution of L-type $\mathrm{Ca}^{2+}$ channels in motoneurons based on variable threshold of activation of persistent inward currents. J Neurophysiol 95:225-241.

Bui TV, Grande G, Rose PK (2008a) Multiple modes of amplification of synaptic inhibition to motoneurons by persistent inward currents. J Neurophysiol 99:571-582.

Bui TV, Grande G, Rose PK (2008b) Relative location of inhibitory synapses and persistent inward currents determines the magnitude and mode of synaptic amplification in motoneurons. J Neurophysiol 99:583-594.

Burke RE, Glenn LL (1996) Horseradish peroxidase study of the spatial and electrotonic distribution of group Ia synapses on type-identified ankle extensor motoneurons in the cat. J Comp Neurol 372:465-485.

Carlin KP, Jones KE, Jiang Z, Jordan LM, Brownstone RM (2000) Dendritic L-type calcium currents in mouse spinal motoneurons: implications for bistability. Eur J Neurosci 12:1635-1646.

Cullheim S, Fleshman JW, Glenn LL, Burke RE (1987) Membrane area and dendritic structure in type-identified triceps surae alpha motoneurons. J Comp Neurol 255:68-81.

Cushing S, Bui T, Rose PK (2005) Effect of nonlinear summation of synaptic currents on the input-output properties of spinal motoneurons. J Neurophysiol 94:3465-3478.

Delgado-Lezama R, Perrier JF, Hounsgaard J (1999) Local facilitation of plateau potentials in dendrites of turtle motoneurones by synaptic activation of metabotropic receptors. J Physiol 515:203-207.

Elbasiouny SM, Bennett DJ, Mushahwar VK (2006) Simulation of $\mathrm{Ca}^{2+}$ persistent inward currents in spinal motoneurones: mode of activation and integration of synaptic inputs. J Physiol 570:355-374.

Fyffe RE (1991) Spatial distribution of recurrent inhibitory synapses on spinal motoneurons in the cat. J Neurophysiol 65:1134-1149.

Fyffe RE (2001) Spinal motoneurons: synaptic inputs and receptor organization. In: Motor neurobiology of the spinal cord (Cope TC, ed). New York: CRC

Gottmann K, Dietzel ID, Lux HD, Huck S, Rohrer H (1988) Development of inward currents in chick sensory and autonomic neuronal precursor cells in culture. J Neurosci 8:3722-3732.

Gottmann K, Rohrer H, Lux HD (1991) Distribution of $\mathrm{Ca}^{2+}$ and $\mathrm{Na}^{+}$ conductances during neuronal differentiation of chick DRG precursor cells. J Neurosci 11:3371-3378.

Grande G, Armstrong S, Neuber-Hess M, Rose PK (2005) Distribution of contacts from vestibulospinal axons on the dendrites of splenius motoneurons. J Comp Neurol 491:339-351.

Grande G, Bui TV, Rose PK (2007a) Estimates of the location of L-type $\mathrm{Ca}^{2+}$ channels in motoneurons of different sizes: a computational study. J Neurophysiol 97:4023-4035.

Grande G, Bui TV, Rose PK (2007b) Effect of localized innervation of the dendritic trees of feline motoneurons on the amplification of synaptic input: a computational study. J Physiol 583:611-630.

Heckman CJ, Lee RH (1999) Synaptic integration in bistable motoneurons. Prog Brain Res 123:49-56.

Heckman CJ, Lee RH, Brownstone RM (2003) Hyperexcitable dendrites in motoneurons and their neuromodulatory control during motor behavior. Trends Neurosci 26:688-695.

Hille B (2001) Ion channels of excitable membranes. Sunderland, MA: Sinauer.

Hounsgaard J, Kiehn O (1985) $\mathrm{Ca}^{++}$dependent bistability induced by serotonin in spinal motoneurons. Exp Brain Res 57:422-425.

Hounsgaard J, Kiehn O (1989) Serotonin-induced bistability of turtle motoneurones caused by a nifedipine-sensitive calcium plateau potential. J Physiol 414:265-282.

Hounsgaard J, Kiehn O (1993) Calcium spikes and calcium plateaux evoked by differential polarization in dendrites of turtle motoneurones in vitro. J Physiol 468:245-259.

Hounsgaard J, Mintz I (1988) Calcium conductance and firing properties of spinal motoneurones in the turtle. J Physiol 398:591-603.

Hultborn H, Denton ME, Wienecke J, Nielsen JB (2003) Variable amplification of synaptic input to cat spinal motoneurones by dendritic persistent inward current. J Physiol 552:945-952.

Jonas P, Bischofberger J, Sandkuhler J (1998) Corelease of two fast neurotransmitters at a central synapse. Science 281:419-424.

Jones SM, Lee RH (2006) Fast amplification of dynamic synaptic inputs in spinal motoneurons in vivo. J Neurophysiol 96:2200-2206.

Kuo JJ, Lee RH, Johnson MD, Heckman HM, Heckman CJ (2003) Active dendritic integration of inhibitory synaptic inputs in vivo. J Neurophysiol 90:3617-3624.

Lee RH, Heckman CJ (1996) Influence of voltage-sensitive dendritic conductances on bistable firing and effective synaptic current in cat spinal motoneurons in vivo. J Neurophysiol 76:2107-2110.

Lee RH, Heckman CJ (2000) Adjustable amplification of synaptic input in the dendrites of spinal motoneurons in vivo. J Neurosci 20:6734-6740.

Li Y, Bennett DJ (2003) Persistent sodium and calcium currents cause plateau potentials in motoneurons of chronic spinal rats. J Neurophysiol 90:857-869.

Li Y, Brewer D, Burke RE, Ascoli GA (2005) Developmental changes in spinal motoneuron dendrites in neonatal mice. J Comp Neurol 483:304-317.

Loewenstein Y, Sompolinsky H (2003) Temporal integration by calcium dynamics in a model neuron. Nat Neurosci 6:961-967.

Moritz AT, Newkirk G, Powers RK, Binder MD (2007) Facilitation of so- 
matic calcium channels can evoke prolonged tail currents in rat hypoglossal motoneurons. J Neurophysiol 98:1042-1047.

Müller W, Lux HD (1993) Analysis of voltage-dependent membrane currents in spatially extended neurons from point-clamp data. J Neurophysiol 69:241-247.

Poirazi P, Mel BW (2001) Impact of active dendrites and structural plasticity on the memory capacity of neural tissue. Neuron 29:779-796.

Poirazi P, Brannon T, Mel BW (2003a) Arithmetic of subthreshold synaptic summation in a model CA1 pyramidal cell. Neuron 37:977-987.

Poirazi P, Brannon T, Mel BW (2003b) Pyramidal neuron as two-layer neural network. Neuron 37:989-999.

Powers RK, Nardelli P, Cope TC (2008) Estimation of the contribution of intrinsic currents to motoneuron firing based on paired motoneuron discharge records in the decerebrate cat. J Neurophysiol 100:292-303.

Prather JF, Powers RK, Cope TC (2001) Amplification and linear summation of synaptic effects on motoneuron firing rate. J Neurophysiol 85:43-53.

Rall W, Burke RE, Smith TG, Nelson PG, Frank K (1967) Dendritic location of synapses and possible mechanisms for the monosynaptic EPSP in motoneurons. J Neurophysiol 30:1169-1193.

Reuveni I, Friedman A, Amitai Y, Gutnick MJ (1993) Stepwise repolariza- tion from $\mathrm{Ca}^{2+}$ plateaus in neocortical pyramidal cells: evidence for nonhomogeneous distribution of HVA $\mathrm{Ca}^{2+}$ channels in dendrites. J Neurosci 13:4609-4621.

Schwindt PC, Crill WE (1980) Properties of a persistent inward current in normal and TEA-injected motoneurons. J Neurophysiol 43:1700-1724.

Shapiro NP, Lee RH (2007) Synaptic amplification versus bistability in motoneuron dendritic processing: a top-down modeling approach. J Neurophysiol 97:3948-3960.

Simon M, Perrier JF, Hounsgaard J (2003) Subcellular distribution of L-type $\mathrm{Ca}^{2+}$ channels responsible for plateau potentials in motoneurons from the lumbar spinal cord of the turtle. Eur J Neurosci 18:258-266.

Westenbroek RE, Hoskins L, Catterall WA (1998) Localization of $\mathrm{Ca}^{2+}$ channel subtypes on rat spinal motor neurons, interneurons, and nerve terminals. J Neurosci 18:6319-6330.

Zhang M, Møller M, Broman J, Sukiasyan N, Wienecke J, Hultborn H (2008) Expression of calcium channel CaV1.3 in cat spinal cord: light and electron microscopic immunohistochemical study. J Comp Neurol 507:1109-1127. 